\title{
Fabrication and Characterization of Viton@FOX-7@Al Spherical Composite with Improved Thermal Decomposition Property and Safety Performance
}

\author{
Xiaodong Li *, Yue Yang *(D), Changgui Song, Yantao Sun, Yuanqi Han $\mathbb{D}^{\mathbb{C}}$, Yue Zhao and Jingyu Wang \\ School of Environment and Safety Engineering, North University of China, Jiancaoping District, Taiyuan 030051, \\ China; song986522760@163.com (C.S.); sunyt@nuc.edu.cn (Y.S.); Cadits@yeah.net (Y.H.); \\ yy080044@126.com (Y.Z.); wjywjy67@163.com (J.W.) \\ * Correspondence: lixd78@126.com (X.L.); yy.amie@foxmail.com (Y.Y.)
}

Citation: Li, X.; Yang, Y.; Song, C.; Sun, Y.; Han, Y.; Zhao, Y.; Wang, J. Fabrication and Characterization of Viton@FOX-7@Al Spherical Composite with Improved Thermal Decomposition Property and Safety Performance. Materials 2021, 14, 1093. https://doi.org/10.3390/ma14051093

Academic Editor: Gabriele Milani

Received: 5 January 2021

Accepted: 11 February 2021

Published: 26 February 2021

Publisher's Note: MDPI stays neutral with regard to jurisdictional claims in published maps and institutional affiliations.

Copyright: (c) 2021 by the authors. Licensee MDPI, Basel, Switzerland. This article is an open access article distributed under the terms and conditions of the Creative Commons Attribution (CC BY) license (https:/ / creativecommons.org/licenses/by/ $4.0 /)$.

\begin{abstract}
To achieve a uniform distribution of the components and a better performance of aluminized composite explosives, Viton (dipolymers of hexafluoropropylene and vinylidene fluoride) @ FOX-7 (1,1-diamino-2,2-dinitroethylene) @Al microspheres and FOX-7/Viton@Al were synthesized by spray-drying strategy contrastively. Viton@FOX-7@Al owned porous and loose morphology and good sphericity with a retained crystal phase of FOX-7 and aluminum. The $23.56 \%$ fluorine content on Viton@FOX-7@Al surface indicated that Viton was completely coated on the surface of the particles. Nanosized aluminum (nAl) in Viton@FOX-7@Al had a certain catalytic activity on the thermal decomposition process of FOX-7 resulting in a depressed exothermic peak temperature and reduced apparent activation energy relative to nAl in FOX-7/Viton@Al. Because of the specific structure and the synergies between each individual component, Viton@FOX-7@Al showed reduced impact sensitivity and friction sensitivity than those of FOX-7/Viton@Al. In brief, Viton@FOX-7@Al with multilevel coating structure possessed comparatively low thermal decomposition energy requirement and improved safety performance.
\end{abstract}

Keywords: FOX-7 (1,1-diamino-2,2-dinitroethylene); thermal decomposition analysis; energetic materials; aluminized composite explosives

\section{Introduction}

Aluminized composite explosives are usually composed of heterogeneous components, including explosive crystals as high-energy components, polymers as binders and aluminum powder as the main metal fuel. Due to the high energy output and explosion heat, aluminized composite explosives are widely used in advanced weapon systems. [1-3]. Aluminum powder is used as a fuel additive to increase the energy of the air blast wave, the bubble energy in underwater explosions, and the duration of combustion action in aluminized composite explosives [4-6]. Compared to micrometer-sized particles, nano-sized aluminum (nAl) particles own high special surface areas and enhanced contact areas with explosives, so as to achieve more complete and faster oxidation [4,7].

However, because of the inevitable aggregation of $\mathrm{nAl}$ and the significant difference in particle size distribution between $\mathrm{nAl}$ and explosive particles, the distribution of different components is generally inhomogenous, which greatly limits the performance of aluminized composite explosives [8]. To achieve uniform distribution of the additives, spray-drying as a facile way of assembling heterogeneous components could be applied in the preparation of composite energetic materials $[6,9,10]$. The spray-drying method was applied to fabricate TATB-wrapped HMX composites with micro-sized HMX particles embedded uniformly into the TATB encapsulation. The results indicated that the spray-drying technique was a facile and preferred strategy for the formation of core-shell energetic composites with high performance [11]. Ji et al. adopted a suspension spraydrying method to prepare solid spherical $\mathrm{HMX} / \mathrm{F}_{2602}$ possessing good thermal stability and 
lowered mechanical sensitivity [12], which denoted spray-drying as a promising method for the preparation of the energetic particles with desirable structure.

Herein, the Viton@FOX-7@Al microspheres and FOX-7/Viton@Al were fabricated contrastively by spray-drying through solvent volatilization and the precipitation of FOX-7 and Viton. The morphology and composition of recrystallized FOX-7, nAl, Viton@FOX-7@Al and FOX-7/Viton@Al were measured and analyzed. The thermal properties and mechanical sensitivity of the three samples were further characterized. Our work demonstrated a facile and effective spray-drying method for preparing aluminized composite explosives with controlled structure and improved performance, providing a good combination of technology and material structure.

\section{Materials and Methods}

\subsection{Sample Preparation}

The materials used herein were recrystallized FOX-7 (purity 99.5\%), which was prepared from pristine FOX-7 [13] (Modern Chemistry Research Institute of China, Xi'an) in our laboratory, 50-100 nm aluminum powders (nAl, Beijing Flance Nanotechnology Co., Ltd., Beijing, China) and Viton (Bluestar Chengrand Co., Chengdu, China). The reagents used in this study were dimethylformamide (DMF, AR, Tansoole, Shanghai, China) and ethyl acetate (EtAc, AR, Tansoole, Shanghai, China).

The preparation of two different suspensions: $0.20 \mathrm{~g}$ Viton was dissolved in $96 \mathrm{~mL}$ DMF and EtAc to form two different transparent solutions, respectively. The recrystallized FOX-7 grains $(3.00 \mathrm{~g})$ and $\mathrm{nAl}(0.80 \mathrm{~g})$ were added into the two different Viton solutions, respectively. Two different uniform suspensions were formed after stirring ( $300 \mathrm{rpm})$ and sonication $(650 \mathrm{~W})$ for $30 \mathrm{~min}$ (DMF: nAl suspended in FOX-7/Viton co-solution; EtAc: FOX-7 and nAl suspended in Viton solution) for further preparation of the composites.

The preparation of two different composites: two kinds of aluminized FOX-7 based composites were obtained by spray-drying (Figure S1) under the same experimental conditions (using a feed rate of $4.5 \mathrm{~mL} \cdot \mathrm{min}^{-1}$, a nitrogen flow rate of $336 \mathrm{~L} \cdot \mathrm{h}^{-1}$, an inlet temperature of $90{ }^{\circ} \mathrm{C}$ and a spray cap with a $1.4 \mathrm{~mm}$ hole). A blackish green powder (Viton@FOX-7@Al) and a yellow green powder (FOX-7/Viton@Al) were collected after $30 \mathrm{~min}$.

\subsection{Characterization}

The characterization of the composition, morphology and crystalline structures of the three samples was performed by field-emission scanning electron microscopy (FE-SEM; S4800, Hitachi, Tokyo, Japan), transmission electron microscope (TEM, JEOL JEM-2100F, Tokyo, Japan), X-ray powder diffraction (XRD; DX-2700 Dandong Haoyuan, using Cu Ka radiation, Dandong, Liaoning, PR China) and X-ray photo electron spectroscopy (XPS; Thermo ESCALAB 250Xi X-ray photoelectron spectrometer, Carlsbad, CA, USA), respectively. The program Nano Measurer 1.2 was utilized for size measurement. Differential scanning calorimetry (DSC) was characterized on a TA Q2000 instrument (TA Instruments, NewCastle, DE USA) at the heating rate of $5,10,15$, and $20^{\circ} \mathrm{C} \cdot \mathrm{min}^{-1}$ ranging from $50{ }^{\circ} \mathrm{C}$ to $350^{\circ} \mathrm{C}$ under air atmosphere. The impact sensitivity and friction sensitivity of the three samples were tested according to the Chinese National Military Standard (GJB-772A-97) [14] method 601.3 with an ERL Type 12 drop-hammer instrument and the GJB-772A-97 method 602.1 with a WM-type friction sensitivity apparatus, respectively (See Figures S4 and S5).

\section{Results}

\subsection{XRD Analysis}

XRD was utilized in detecting the phase composition of the prepared samples. Figure 1 depicts the XRD patterns of nAl, recrystallized FOX-7, FOX-7/Viton@Al and Viton@FOX7@Al. All of the diffraction peaks of nAl were perfectly matched to the aluminum (JCPDS No. 04-0787) with no aluminum oxide peaks found [15]. Meanwhile, FOX-7/Viton@Al and Viton@FOX-7@Al both showed diffraction peaks of FOX-7 crystal and nAl and the 
significantly weakened diffraction peak intensity of $\mathrm{nAl}$ indicated that the $\mathrm{nAl}$ surface had been completely coated in two different structured composites.

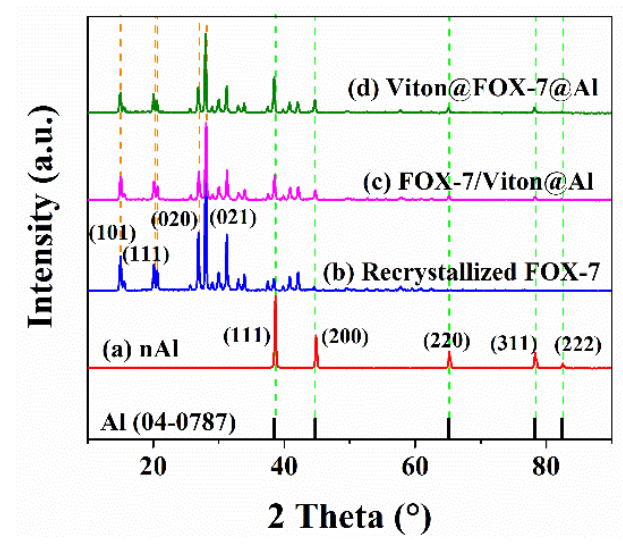

Figure 1. XRD patterns of (a) nAl; (b) recrystallized FOX-7; (c) FOX-7/Viton@Al and (d) Viton@FOX$7 @ A l$. The XRD patterns were measured within the $2 \theta$ range of $10^{\circ} \sim 90^{\circ}$ at a scan speed of $0.5^{\circ} \cdot \mathrm{min}^{-1}$.

\subsection{XPS Analysis}

The XPS tests were carried out to illustrate the surface elemental composition and chemical state of the three samples, namely recrystallized FOX-7, FOX-7/Viton@Al and Viton@FOX-7@Al. The survey spectra showed that the major elements on the surface of recrystallized FOX-7 were $\mathrm{C}, \mathrm{N}$ and $\mathrm{O}$ and the major elements on the surface of FOX7/Viton@Al and Viton@FOX-7@Al were C, N, O, F and Al (Figure 2). The intensity of N and $\mathrm{O}$ element content in the two coated samples was apparently reduced, indicating a depressed amount of FOX-7 on the surface of the two composites. The element content of $\mathrm{Al}$ on the surface of FOX-7/Viton@Al and Viton@FOX-7@Al was 0.87\% and 2.42\% respectively, which denotes good coating effect of Viton and FOX-7 on nAl surface. The content of fluorine on the surface of the Viton@FOX-7@Al was relatively high, while the content of oxygen and nitrogen on the surface of the Viton@FOX-7@Al was reduced, indicating that the Viton was mainly distributed and coated on the surface of Viton@FOX-7@Al although the content of Viton in the precursor was lower than that of FOX-7.

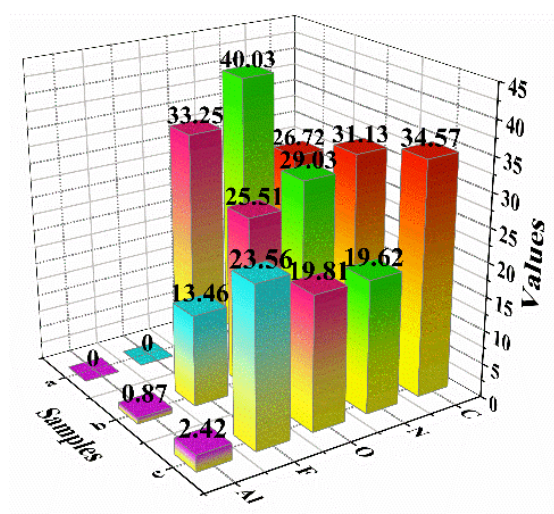

Figure 2. Quantification of element species on the surface of the three samples through analysis of XPS: (a) recrystallized FOX-7, (b) FOX-7/Viton@Al and (c) Viton@FOX-7@Al.

The C1s peaks of recrystallized FOX-7 appeared at $284.77(\mathrm{C}-\mathrm{C}), 286.80\left(\mathrm{C}-\mathrm{NH}_{2}\right)$, $288.49\left(\mathrm{C}-\mathrm{NO}_{2}\right), 292.00\left(\pi-\pi^{*}\right.$ molecular transition) (Figure $\left.3 \mathrm{~b}\right)$, which is in agreement with the crystal structure of FOX-7 in reference [16]. Compared with recrystallized FOX-7, the peaks of FOX-7/Viton@Al and Viton@FOX-7@Al assigned to $\pi-\pi^{*}$ molecular transition were completely covered by two appeared peaks corresponding to $-\mathrm{CF}_{2}$ and $-\mathrm{CF}_{3}$, which confirmed that Viton was incorporated into two spray-dried composites respectively. 
The intensity of F1s peak of Viton@FOX-7@Al was apparently higher than that of FOX7/Viton@Al, indicating a higher coverage of Viton on the Viton@FOX-7@Al surface. The detailed spectra over the Al2p peaks for FOX-7/Viton@Al and Viton@FOX-7@Al are shown in Figure $3 \mathrm{~g}, \mathrm{~h}$. The spectra could be fitted as a high binding energy peak and a low shoulder peak [17], corresponding to $\mathrm{Al}$ in some oxidized form and metal $\mathrm{Al}$ in the core of composites, respectively. Evidently, the relative intensity for Al2p in FOX-7/Viton@Al was lower, which indicated the coating of Viton on nAl without covering the surface of FOX-7.
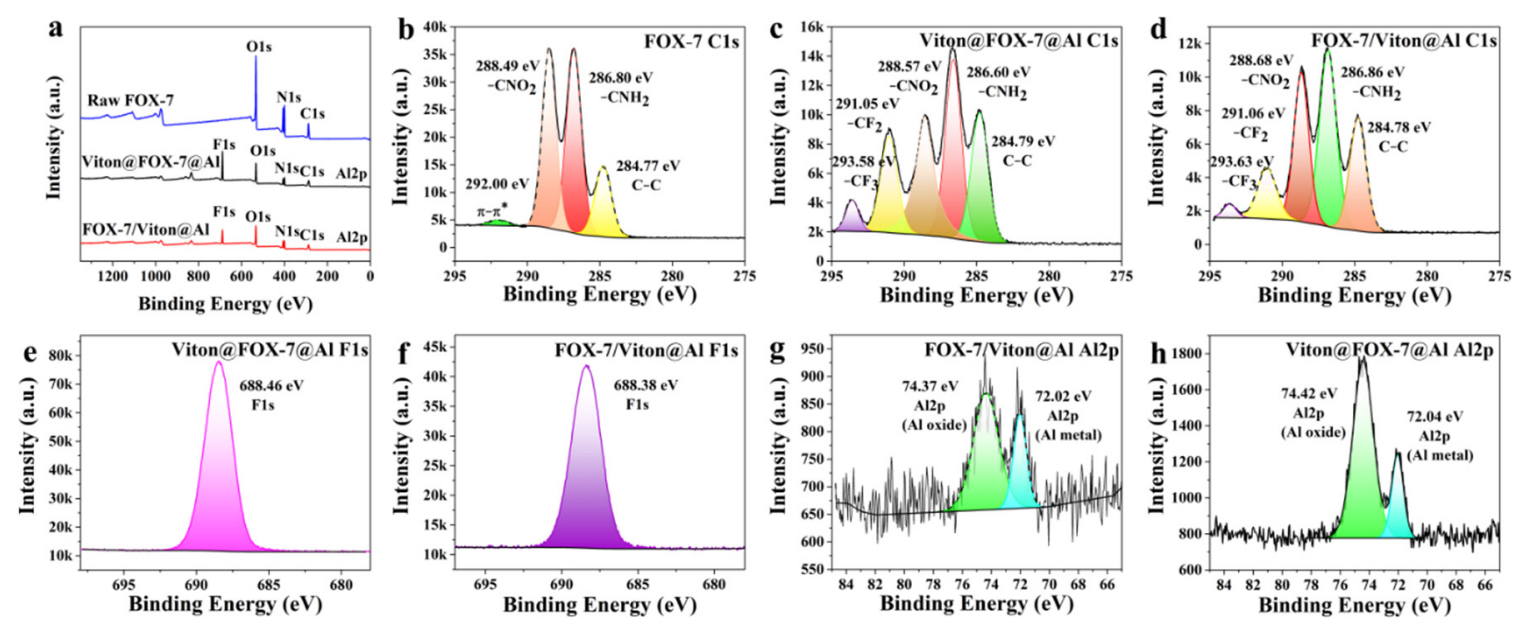

Figure 3. (a) XPS survey spectra of the three samples; The detailed spectra of the C1s peaks for (b) recrystallized FOX-7; (c) FOX-7/Viton@Al and (d) Viton@FOX-7@Al; the detailed spectra of the F1s peaks for (e) FOX-7/Viton@Al and (f) Viton@FOX-7@Al; the detailed spectra of the Al2p peaks for (g) FOX-7/Viton@Al and (h) Viton@FOX-7@Al.

\subsection{Morphology Analysis}

As shown in Figure 4, the morphology of nAl, recrystallized FOX-7, FOX-7/Viton@Al and Viton@FOX-7@Al were obtained by SEM measurement. The perfect spherical shape of $\mathrm{nAl}$ could be observed in Figure $4 \mathrm{a}$. As shown in Figure $4 \mathrm{~b}$ and Figure S2, the oxide thickness of $\mathrm{nAl}$ was about $1 \sim 2 \mathrm{~nm}$, indicating good reactive activity of $\mathrm{nAl}$. The recrystallized FOX-7 grains are shown in Figure 4c, displaying cubic crystals with the particle size centralized in the range of $0.63 \sim 2.22 \mu \mathrm{m}$. The morphology of FOX-7/Viton@Al and Viton@FOX-7@Al composites obtained by the spray-drying process are shown in Figure $4 \mathrm{~d}, \mathrm{f}$, respectively. As shown in Figure $4 \mathrm{~d}$, the surface of FOX-7 grains in FOX7/Viton@Al was almost bare without the covering from Viton, which was in conformity with the aforementioned XPS results. The particle size of FOX-7/Viton@Al was the same as that of recrystallized FOX-7, while Viton was mainly coated on the surface of nAl. Contrastingly, Viton@FOX-7@Al was loose and porous microspheres with a particle size of about $3 \mu \mathrm{m}$ showing a completely different morphology from that of recrystallized FOX-7 (Figure S3).

The reason for the appearance of the loose and porous composite spheres of Viton@FOX$7 @ \mathrm{Al}$ could be as explained below (Figure 5). First off, the co-solution of Viton and FOX-7 dispersed with $\mathrm{nAl}$ spheres was atomized into droplets and entered the drying chamber at $90{ }^{\circ} \mathrm{C}$. The DMF on the droplet surface was rapidly evaporated with the heating of drying nitrogen. The condensation of the FOX-7 and Viton formed a dried shell outside the droplets, which reduced the possibility of further adhesion among the droplets [18,19]. Inevitably, the inner DMF carrying solutes was diffused to the surface [20]. The vapor pressure inside the particles increased due to the vaporization of DMF under heating condition. One or more gaps gradually formed in the shell because the surface enrichment of the particles prevented the inner high-pressure steam from dissipating immediately. Meanwhile, components of Viton and FOX-7 wrapped nAl particles were solidified down 
to constitute a thicker shell. Thus, the loose and porous, energetic particles with a certain number of gaps were constructed by a facile spray-drying strategy.

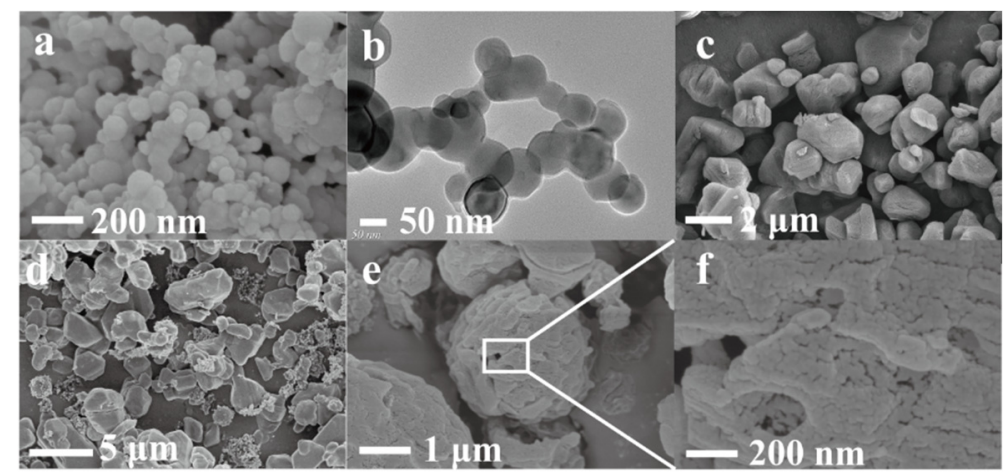

Figure 4. (a) SEM images of nAl, (b) TEM image of nAl, SEM images of (c) recrystallized FOX-7, (d) FOX-7/Viton@Al, (e,f) Viton@FOX-7@Al.

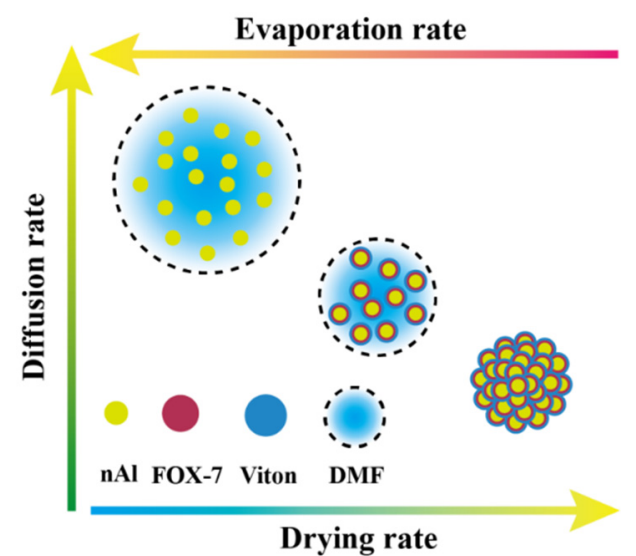

Figure 5. Schematic diagram showing the development of a droplet consisting of the co-solution of FOX-7 and Viton dispersed nAl during the spray-drying process.

\subsection{DSC Analysis}

The thermal decomposition behaviors were obtained according to the DSC curves of three different samples at $5{ }^{\circ} \mathrm{C} \cdot \mathrm{min}^{-1}$. As shown in Figure 6, three different samples had a similar exothermic decomposition process, which indicated that solid-phase decomposition kinetics dominated their thermal decomposition process. The DSC curves showed the first endothermic peak for the $\beta \rightarrow \gamma$ phase transition [21] and the second endothermic peak for the $\gamma \rightarrow \delta$ transition [22]. After the phase transitions, there were two successive exothermic decomposition processes of FOX-7: the first with the peak at ca. $230^{\circ} \mathrm{C}$ corresponding to the emergence of nitro-to-nitrite rearrangement and the second with a main exothermic peak at ca. $290{ }^{\circ} \mathrm{C}$ attributing to the break of the carbon skeleton. Compared with the exothermic peak temperature $\left(T_{p}\right)$ of recrystallized FOX-7 grains, the $T_{p}$ values of the two FOX-7/Al based composites decreased by 6.00 and $17.39^{\circ} \mathrm{C}$, respectively, showing the beneficial effect of $\mathrm{nAl}$ in accelerating the thermal degradation of the FOX-7 molecule. Because of the close interaction between FOX-7 and nAl in multilevel structured Viton@FOX-7@Al, the promotion effect of nAl on the energy release process of FOX-7 in Viton@FOX-7@Al was more obvious than that of FOX-7/Viton@Al.

To achieve the effective evaluation and better functionality of the composite structure formed by FOX-7, $\mathrm{nAl}$ and Viton, it was necessary to estimate the kinetic parameters [23]. We measured $T_{p}$ at different heating rates of $5,10,15$, and $20{ }^{\circ} \mathrm{C} \cdot \mathrm{min}^{-1}$ (Figure 7) and presented averaged apparent activation energy $\left(E_{\alpha}\right)$ values calculated by Kissinger, Starink and Ozawa methods [24-26]. The natural logarithmic value of preexponential factor $(\ln A)$ 
was obtained from $E_{\alpha}$ value calculated by Kissinger method for the first decomposition stage (See Supplementary Materials) and was listed in Table 1.

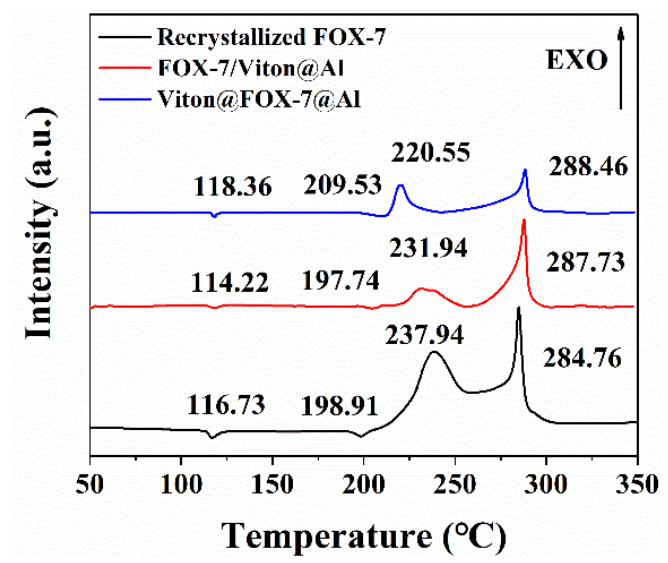

Figure 6. DSC curves of recrystallized FOX-7, FOX-7/Viton@Al and Viton@FOX-7@Al under the heating rate of $5^{\circ} \mathrm{C} \cdot \mathrm{min}^{-1}$.
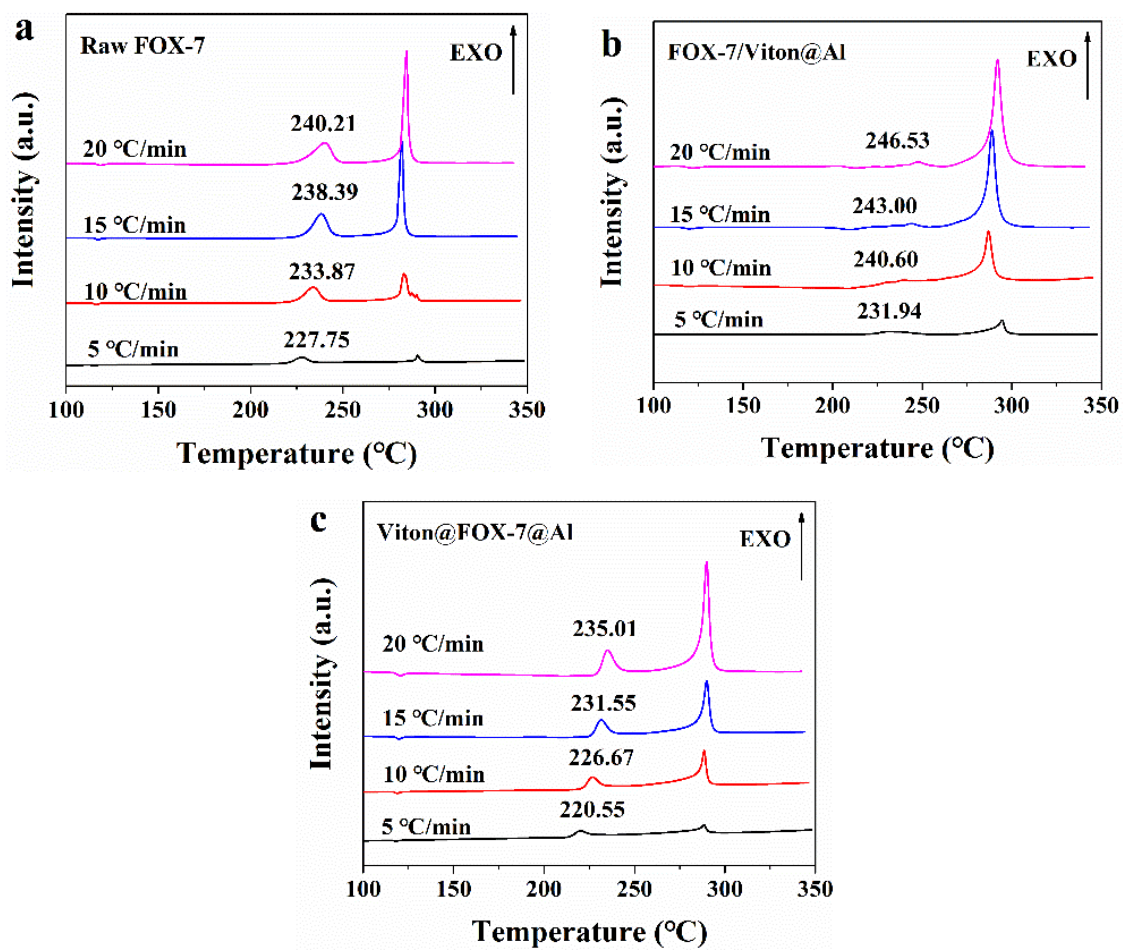

Figure 7. DSC patterns of (a) recrystallized FOX-7, (b) FOX-7/Viton@Al and (c) Viton@FOX-7@Al under the heating rates of $5,10,15$ and $20^{\circ} \mathrm{C} \cdot \mathrm{min}^{-1}$.

Table 1. Thermal decomposition kinetics of samples.

\begin{tabular}{|c|c|c|c|c|c|c|}
\hline \multirow{2}{*}{ Samples } & \multicolumn{3}{|c|}{$E_{a}\left(\mathrm{~kJ} \cdot \mathrm{mol}^{-1}\right)$} & \multirow{2}{*}{$\begin{array}{c}\text { Averaged } E_{a} \\
\left(\mathrm{~kJ} \cdot \mathrm{mol}^{-1}\right)\end{array}$} & \multirow{2}{*}{$\ln A\left(\mathrm{~s}^{-1}\right)$} & \multirow{2}{*}{$r^{2}$} \\
\hline & Kissinger & Starink & Ozawa & & & \\
\hline Recrystallized FOX-7 & 294.56 & 303.13 & 295.42 & 297.70 & 68.87 & 0.9678 \\
\hline FOX-7/Viton@Al & 200.40 & 208.91 & 201.25 & 203.52 & 46.95 & 0.9980 \\
\hline Viton@FOX-7@Al & 190.75 & 199.08 & 191.59 & 193.81 & 45.75 & 0.9914 \\
\hline
\end{tabular}


It is worth noting that the averaged $E_{\alpha}$ value of the initial thermal decomposition process in two composite samples was much lower compared to that of recrystallized FOX7 crystal, which signified nAl had a certain catalytic activity on the thermal degradation of FOX-7 grains. Thus, the decomposition of FOX-7 in the two composites occurred at a lower temperature (with minimum energy requirement). Due to the huge specific area and high surface free energy, nAl tended to absorb gaseous reactive molecules and promote the decomposition reactions of FOX-7 with high catalytic activity $[1,4]$.

The linear relationship between $\ln A$ and $E_{\alpha}$ is considered as the kinetic compensation effect which is widely existed in kinetic studies of solid-state reactions [27]. The values of linear correlation coefficients $r^{2}$ lay between 0.9678 to 0.9980 , which were high enough to represent a good fitting degree of the methods. The values of $E_{\alpha}$ obtained by the three methods were similar, proving that the three methods were appropriate for activation energy threshold calculations. The reduced critical temperature of thermal explosion $\left(T_{b}\right)$ values in Viton@FOX-7@Al and FOX-7/Viton@Al indicated the catalytic effect of nAl on energy release process of the FOX-7 grains.

The analysis of thermodynamic parameters is also an important part along with kinetics for the effectively evaluation of the thermal decomposition properties because these parameters provide fundamental information about the difficulty of activation reaction and thermodynamic equilibrium during the thermal decomposition processes of the samples [28,29]. The calculated results of thermodynamics are listed in Table 2.

Table 2. Critical temperature of thermal explosion $\left(T_{b}\right)$ and thermal decomposition dynamics of samples.

\begin{tabular}{cccccc}
\hline Samples & $\boldsymbol{T}_{\mathbf{0}}\left({ }^{\circ} \mathbf{C}\right)$ & $\boldsymbol{T}_{\boldsymbol{b}}\left({ }^{\circ} \mathbf{C}\right)$ & $\boldsymbol{\Delta S} \neq /\left(\mathrm{J} \cdot \mathbf{m o l}^{\left.-\mathbf{1} \cdot \mathbf{K}^{-\mathbf{1}}\right)}\right.$ & $\boldsymbol{\Delta} \boldsymbol{H} \neq /\left(\mathbf{k J} \cdot \mathbf{m o l}^{-\mathbf{1})}\right.$ & $\boldsymbol{\Delta G} \neq /(\mathbf{k J} \cdot \mathbf{m o l}-\mathbf{1})$ \\
\hline Recrystallized FOX-7 & 223.55 & 230.64 & 315.25 & 290.43 & 133.84 \\
FOX-7/Viton@Al & 216.63 & 224.55 & 133.03 & 196.38 & 132.16 \\
Viton@FOX-7@Al & 213.37 & 223.97 & 123.11 & 186.71 & 126.81 \\
\hline
\end{tabular}

Molecular disorder and randomness of the system are defined by entropy $\left(\Delta S^{\neq}\right)$. The decreased $\Delta S^{\neq}$value indicated a lower degree of disorder of the products compared to that of recrystallized FOX-7. The positive nature of enthalpy $\left(\Delta H^{\neq}\right)$denoted the requirement of heat supplement during thermal decomposition of the samples. Gibbs free energy $\left(\Delta G^{\neq}\right)$is a critical thermodynamic property, which signified the available chemical energy that could be applied to convert reactants into the activated substances. Compared with recrystallized FOX-7, the barely unchanged values of $\Delta G^{\neq}$of the composites revealed that the three samples had sufficient energy to be transited into final state.

\subsection{Mechanical Sensitivity}

The impact sensitivity and friction sensitivity tests of the three different samples were carried out. Table 3 shows the results of sensitivity analysis, reflecting as a $50 \%$ reaction level $\left(H_{50}\right)$ in impact sensitivity and the explosion probability in the friction sensitivity test.

Table 3. Impact sensitivity and friction sensitivity of the samples.

\begin{tabular}{ccc}
\hline Samples & Impact Sensitivity $\mathbf{H}_{\mathbf{5 0}} \mathbf{( c m )}$ & Friction Sensitivity $\mathbf{( \% )}$ \\
\hline Recrystallized FOX-7 & 128.3 & 19 \\
FOX-7/Viton@Al & 135.4 & 12 \\
Viton@FOX-7@Al & $>160$ & 0 \\
\hline
\end{tabular}

The $H_{50}$ values of FOX-7/Viton@Al and Viton@FOX-7@Al were improved from $128.3 \mathrm{~cm}$ (recrystallized FOX-7) to $135.4 \mathrm{~cm}$ and $>160 \mathrm{~cm}$, respectively, and the friction sensitivity of FOX-7/Viton@Al and Viton@FOX-7@Al were reduced from 19\% (recrystallized FOX-7) to $12 \%$ and $0 \%$, respectively (Table 3). The changed values of $H_{50}$ and friction sensitivity indicated that Viton@FOX-7@Al had a better safety performance although FOX-7/Viton@Al and Viton@FOX-7@Al were composed of the same components. 
The mechanism of the mechanical sensitivity reduction of FOX-7/Viton@Al and Viton@FOX-7@Al could be explained as follows. The high thermal conductivity caused by the addition of $\mathrm{nAl}$ led to a fast heat transfer process in the composites under external stimulation, which could decrease the probability of heat centralization and further reduce hot-spot generation [30,31]. Besides, Viton as the cladding material formed a buffer layer on the surface of FOX-7 and nAl, decreasing the external stimuli impacted on the surface of FOX-7 and nAl [32]. Moreover, Viton@FOX-7@Al had a multilevel structure integrated by Viton and FOX-7, providing a higher surface area of FOX-7 than that of FOX-7 in FOX7/Viton@Al. Compared with FOX-7/Viton@Al, the high surface area of FOX-7 and close contact between FOX-7 and nAl accelerated the heat transfer rate in Viton@FOX-7@Al when suffering from rapid and intensive mechanical impact and friction.

\section{Conclusions}

To sum up, FOX-7/Viton@Al and Viton@FOX-7@Al with different structures were successfully synthesized by the spray-drying method. Viton@FOX-7@Al with loose and porous spherical shape had a higher fluorine content on the surface, which indicated that the surface of $\mathrm{nAl}$ was fully coated. The reduced values of apparent activation energy and exothermic peak maximum showed that the catalytic effect of nAl in Viton@FOX7@Al was superior to that in FOX-7/Viton@Al. Viton@FOX-7@Al had lower impact and friction sensitivity relative to FOX-7/Viton@Al, which confirmed that multilevel structured Viton@FOX-7@Al had higher safety performance. This study shows that Viton@FOX-7@Al has considerable potential for further application in the field of composite solid propellant.

Supplementary Materials: The following are available online at https:/ /www.mdpi.com/1996-194 4/14/5/1093/s1, Figure S1: Schematic diagram of spray-drying device. Figure S2 (a) TEM image of nAl, (b) the oxide thickness of nAl from the TEM image. Figure S3 (a) SEM image of Viton@FOX-7@Al, (b) the particle size distribution of Viton@FOX-7@Al from the SEM image. Figure S4: Illustration of HGZ-1 impact instrument. Figure S5: Experimental set-up for measuring friction sensitivity.

Author Contributions: Conceptualization and methodology, C.S., Y.Z., and Y.H.; validation, Y.S., Y.Z., and Y.H.; formal analysis, X.L. and Y.S.; investigation, X.L. and Y.Y.; resources, X.L. and J.W.; data curation, Y.Y.; writing-original draft preparation, Y.Y.; writing—review and editing, X.L.; visualization, J.W.; supervision, J.W. All authors have read and agreed to the published version of the manuscript.

Funding: This research was supported by the Scientific and Technological Innovation Programs of Higher Education in Shanxi Province of China (Grant No. 2019L0524).

Data Availability Statement: The data presented in this study are available in supplementary material.

Acknowledgments: The authors would like to thank Tingting Fan from Shiyanjia Lab (www. shiyanjia.com) for the XPS analysis.

Conflicts of Interest: The authors declare no conflict of interest.

\section{References}

1. Singh, A.; Soni, P.K.; Sarkar, C.; Mukherjee, N. Thermal reactivity of aluminized polymer-bonded explosives based on nonisothermal thermogravimetry and calorimetry measurements. J. Therm. Anal. Calorim. 2018, 136, 1021-1035. [CrossRef]

2. Ji, X.; Tang, D.; Li, Y.; Xing, Z.; Wang, Y.; Wang, L.; Gao, Y.; Qin, W. Influence of aluminum nanoparticles and binders on the laser initiation of cyclotrimethylenetrinitramine. Opt. Laser Technol. 2019, 120, 105677. [CrossRef]

3. Elia, T.; Baudin, G.; Genetier, M.; Lefrançois, A.; Osmont, A.; Catoire, L. Shock to Detonation Transition of Plastic Bonded Aluminized Explosives. Propellants Explos. Pyrotech. 2019, 45, 554-567. [CrossRef]

4. Zhu, Y.-L.; Huang, H.; Ren, H.; Jiao, Q.-J. Influence of Aluminum Particle Size on Thermal Decomposition of RDX. J. Energetic Mater. 2013, 31, 178-191. [CrossRef]

5. Xiao, L.; Zhang, Y.; Wang, X.; Hao, G.; Liu, J.; Ke, X.; Chen, T.; Jiang, W. Preparation of a superfine RDX/Al composite as an energetic material by mechanical ball-milling method and the study of its thermal properties. RSC Adv. 2018, 8, 38047-38055. [CrossRef] 
6. Sun, H.; Li, X.; Wu, P.; Song, C.; Yang, Y. Preparation and Properties of RDX/Aluminum Composites by Spray-Drying Method. J. Nanomater. 2020, 2020, 1-8. [CrossRef]

7. Hao, W.; Li, G.; Niu, L.; Gou, R.-J.; Zhang, C. Molecular Dynamics Insight into the Evolution of Al Nanoparticles in the Thermal Decomposition of Energetic Materials. J. Phys. Chem. C 2020, 124, 10783-10792. [CrossRef]

8. Yan, T.; Ren, H.; Liu, J.; Jiao, Q. Facile preparation and synergetic energy releasing of nano-Al@RDX@Viton hollow microspheres. Chem. Eng. J. 2020, 379, 122333. [CrossRef]

9. Nandiyanto, A.B.D.; Okuyama, K. Progress in developing spray-drying methods for the production of controlled morphology particles: From the nanometer to submicrometer size ranges. Adv. Powder Technol. 2011, 22, 1-19. [CrossRef]

10. Zainuddin, M.I.; Tanaka, S.; Furushima, R.; Uematsu, K. Correlation between slurry properties and structures and properties of granules. J. Eur. Ceram. Soc. 2010, 30, 3291-3296. [CrossRef]

11. Ma, Z.; Gao, B.; Wu, P.; Shi, J.; Qiao, Z.; Yang, Z.; Yang, G.; Huang, B.; Nie, F. Facile, continuous and large-scale production of core-shell HMX@TATB composites with superior mechanical properties by a spray-drying process. RSC Adv. 2015, 5, 21042-21049. [CrossRef]

12. Ji, W.; Li, X.; Wang, J.; Ye, B.; Wang, C. Preparation and Characterization of the Solid Spherical HMX/F2602by the Suspension Spray-Drying Method. J. Energetic Mater. 2016, 34, 357-367. [CrossRef]

13. Li, X.; Yang, W.; Liu, H. Recrystallize FOX-7 by Spray Recrystallization Method and Its Performance Characterization. J. Propellants, Explos. 2020, 43, 662-668. (In Chinese)

14. Technology and Industry for National Defense of China. Experimental Methods of Sensitivity and Safety; GJB/772A-97; National Military Standard of China. Costind Army Standard Publishing House: Beijing, China, 1997. (In Chinese)

15. Arora, N.; Jagirdar, B.R. Monodispersity and stability: Case of ultrafine aluminium nanoparticles $(<5 \mathrm{~nm})$ synthesized by the solvated metal atom dispersion approach. J. Mater. Chem. 2012, 22, 9058-9063. [CrossRef]

16. Bellamy, A.J. FOX-7 (1,1-Diamino-2,2-dinitroethene). Family Med. 2007, 125, 1-33. [CrossRef]

17. McMahon, B.W.; Perez, J.P.L.; Yu, J.; Boatz, J.A.; Anderson, S.L. Synthesis of Nanoparticles from Malleable and Ductile Metals Using Powder-Free, Reactant-Assisted Mechanical Attrition. ACS Appl. Mater. Interfaces 2014, 6, 19579-19591. [CrossRef]

18. Wu, Z.; Wu, W.D.; Liu, W.; Selomulya, C.; Chen, X.D.; Zhao, D. A General “Surface-Locking” Approach toward Fast Assembly and Processing of Large-Sized, Ordered, Mesoporous Carbon Microspheres. Angew. Chem.-Int. Ed. 2013, 52, 13764-13768. [CrossRef]

19. Liu, D.; Xue, N.; Wei, L.; Zhang, Y.; Qin, Z.; Li, X.; Binks, B.P.; Yang, H. Surfactant Assembly within Pickering Emulsion Droplets for Fabrication of Interior-Structured Mesoporous Carbon Microspheres. Angew. Chem.-Int. Ed. 2018, 57, 10899-10904. [CrossRef]

20. Carné-Sánchez, A.; Imaz, I.; Cano-Sarabia, M.; Maspoch, D. A spray-drying strategy for synthesis of nanoscale metal-organic frameworks and their assembly into hollow superstructures. Nat. Chem. 2013, 5, 203-211. [CrossRef] [PubMed]

21. Zhang, Y.; Hou, C.; Jia, X.; Wang, J.; Tan, Y. Fabrication of Nanoparticle-Stacked 1,1-Diamino-2,2-Dinitroethylene (FOX-7) Microspheres with Increased Thermal Stability. J. Nanomater. 2019, 2019, 1-9. [CrossRef]

22. Chatragadda, K.; Vargeese, A.A. A Kinetics Investigation on the Nitro-Nitrite Rearrangement Mediated Thermal Decomposition of High Temperature Monoclinic Phase of 1,1-Diamino-2,2-Dinitroethylene ( $\gamma$-Fox-7). J. Chem. Sci. 2017, 129, 281-288. [CrossRef]

23. Li, X.; Zhang, X.; Yang, W.; Song, C.; Sun, H.; Wang, J. Design and Characterization of a Cook-Off Resistant High-Energy Booster Explosive Based on CL-20/FOX-7. Propellants, Explos. Pyrotech. 2019, 44, 550-556. [CrossRef]

24. Kissinger, H.E. Reaction Kinetics in Differential Thermal Analysis. Anal. Chem. 1957, 29, 1702-1706. [CrossRef]

25. Starink, M. The determination of activation energy from linear heating rate experiments: A comparison of the accuracy of isoconversion methods. Thermochim. Acta 2003, 404, 163-176. [CrossRef]

26. Ozawa, T. A New Method of Analyzing Thermogravimetric Data. Bull. Chem. Soc. Jpn. 1965, 38, 1881-1886. [CrossRef]

27. Barrie, P.J. The mathematical origins of the kinetic compensation effect: 1 . The effect of random experimental errors. Phys. Chem. Chem. Phys. 2012, 14, 318-326. [CrossRef]

28. Gupta, S.; Gupta, G.K.; Mondal, M.K. Thermal degradation characteristics, kinetics, thermodynamic, and reaction mechanism analysis of pistachio shell pyrolysis for its bioenergy potential. Biomass Convers. Biorefinery 2020, 1-15. [CrossRef]

29. Yang, Y.; Li, X.-D.; Sun, Y.-T.; Tian, J.-A.; Liu, H.-M.; Wu, B.-D.; Wang, J.-Y. Preparation and characterization of HMX/EVA/hBNNSs micro-composites with improved thermal stability and reduced sensitivity. Def. Technol. 2020. [CrossRef]

30. Field, J.E. Hot spot ignition mechanisms for explosives. Accounts Chem. Res. 1992, 25, 489-496. [CrossRef]

31. He, G.; Yang, Z.; Zhou, X.; Zhang, J.; Pan, L.; Liu, S. Polymer bonded explosives (PBXs) with reduced thermal stress and sensitivity by thermal conductivity enhancement with graphene nanoplatelets. Compos. Sci. Technol. 2016, 131, 22-31. [CrossRef]

32. Wang, J.; Ye, B.; An, C.; Wu, B.; Li, H.; Wei, Y. Preparation and Properties of Surface-Coated HMX with Viton and Graphene Oxide. J. Energetic Mater. 2016, 34, 235-245. [CrossRef] 